This work is licensed under a Creative Commons Attribution 3.0 License.

\title{
New species of "giant" plume moths of the genus Platyptilia (Lepidoptera, Pterophoridae) from Uganda
}

\author{
Peter USTJUZHANIN ${ }^{1}$, Vasiliy KOVTUNOVICH ${ }^{2}$ \& Anna USTJUZHANINA ${ }^{3, *}$ \\ ${ }^{1}$ Altai State University, Lenina 61, Barnaul 656049, Russia. \\ ${ }^{2}$ Moscow Society of Nature Explorers. \\ Home address: Malaya Filevskaya str. 24/1, app. 20, Moscow 121433, Russia. \\ ${ }^{3}$ National Research Tomsk Polytechnic University, Lenina 30, Tomsk 634050, Russia.

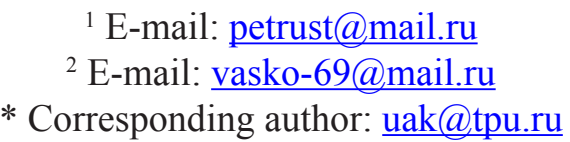 \\ ${ }^{1}$ urn:Isid:zoobank.org:author:60F67CCF-F6C9-4CD4-A2DF-F3216DC46958 \\ ${ }^{2}$ urn:Isid:zoobank.org:author:1959492D-B1A5-45F7-9C11-F079D399B42B \\ ${ }^{3}$ urn:1sid:zoobank.org:author:4A20CB2F-2FA9-4FB6-9983-82E203FFB0E1
}

\begin{abstract}
This paper describes two new species of plume moths from the group of the so-called "giant" Platyptilia Hubner, 1825: Platyptilia fletcheri Ustjuzhanin \& Kovtunovich sp. nov. and P. stanleyi Ustjuzhanin \& Kovtunovich sp. nov. Both species were collected in the Rwenzori Mountains in Uganda and Rwanda, respectively. Platyptilia stanleyi Ustjuzhanin \& Kovtunovich sp. nov. exceeds all the known African species of Pterophoridae in its wingspan of $49 \mathrm{~mm}$.
\end{abstract}

Key words. Pterophoridae, Platyptilia, Uganda, Rwenzori Mountains, new species.

Ustjuzhanin P., Kovtunovich V. \& Ustjuzhanina A. 2016. New species of "giant" plume moths of the genus Platyptilia (Lepidoptera, Pterophoridae) from Uganda. European Journal of Taxonomy 172: 1-6. http://dx.doi. org/10.5852/ejt.2016.172

\section{Introduction}

The genus Platyptilia Hübner, 1825 is widespread all over the world. It is represented by 80 species, more than 40 of them known from Africa (Gielis 2003, 2011). Among them are very large species, having about five centimeters in wingspan. They have been described by Meyrick (1924, 1932, 1938), Gielis $(2008,2011)$ and Kovtunovich \& Ustjuzhanin (2014) and include: Platyptilia aarviki Gielis, 2008, P. daemonica Meyrick, 1932, P. melitroctis Meyrick, 1924, P. postbarbata Meyrick, 1938, P. rhyncholoba Meyrick, 1924, P. nyungwea Gielis, 2011 and P. mugesse Kovtunovich \& Ustjuzhanin, 2014. When examining material at the Natural History Museum, London, we discovered two more new species, belonging to the group of "giant Platyptilia": Platyptilia fletcheri Ustjuzhanin \& Kovtunovich sp. nov. and P. stanleyi Ustjuzhanin \& Kovtunovich sp. nov. Both species were collected during the famous British expeditions to the Rwenzori Mountains in 1934-1935 and 1952, and three specimens were found in Rwanda (T.A. Barns) in 1921. 


\section{Material and methods}

This paper is based on material from the Natural History Museum, London, UK (BMNH). Holotypes and paratypes of the new species are stored in BMNH, and two paratypes of Platyptilia fletcheri Ustjuzhanin \& Kovtunovich sp. nov. are stored in the collections of P. Ustjuzhanin and V. Kovtunovich (CUK, Novosibirsk and Moscow, Russia). The preparation of genitalia is necessary for the identification of Pterophoridae. The dissection was performed with standard methods.

\section{Results}

Class Hexapoda Blainville, 1816

Order Lepidoptera Linnaeus, 1758

Superfamily Pterophoroidea Kuznetsov \& Stekolnikov, 1979

Family Pterophoridae Zeller, 1841

Subfamily Platyptilinae Tutt, 1906

Tribe Platyptilini Bigot, Gibeaux, Nel \& Picard, 1998

Genus Platyptilia Hübner, 1825

Platyptilia fletcheri Ustjuzhanin \& Kovtunovich sp. nov. urn:1sid:zoobank.org:act:785F8238-9629-4217-8417-13973F95CC30

Figs 1-4

\section{Diagnosis}

Platyptilia fletcheri Ustjuzhanin \& Kovtunovich sp. nov. can be distinguished by the large wings and variegated coloring: from dark-brown without any pattern to brown-grey with the pattern of pale areas, spots and dots. In the male genitalia the new species resembles Platyptilia aarviki Gielis, 2008, but clearly differs from it by the shape of the sacculus, the long anellus arms and also the wedge-shaped cut

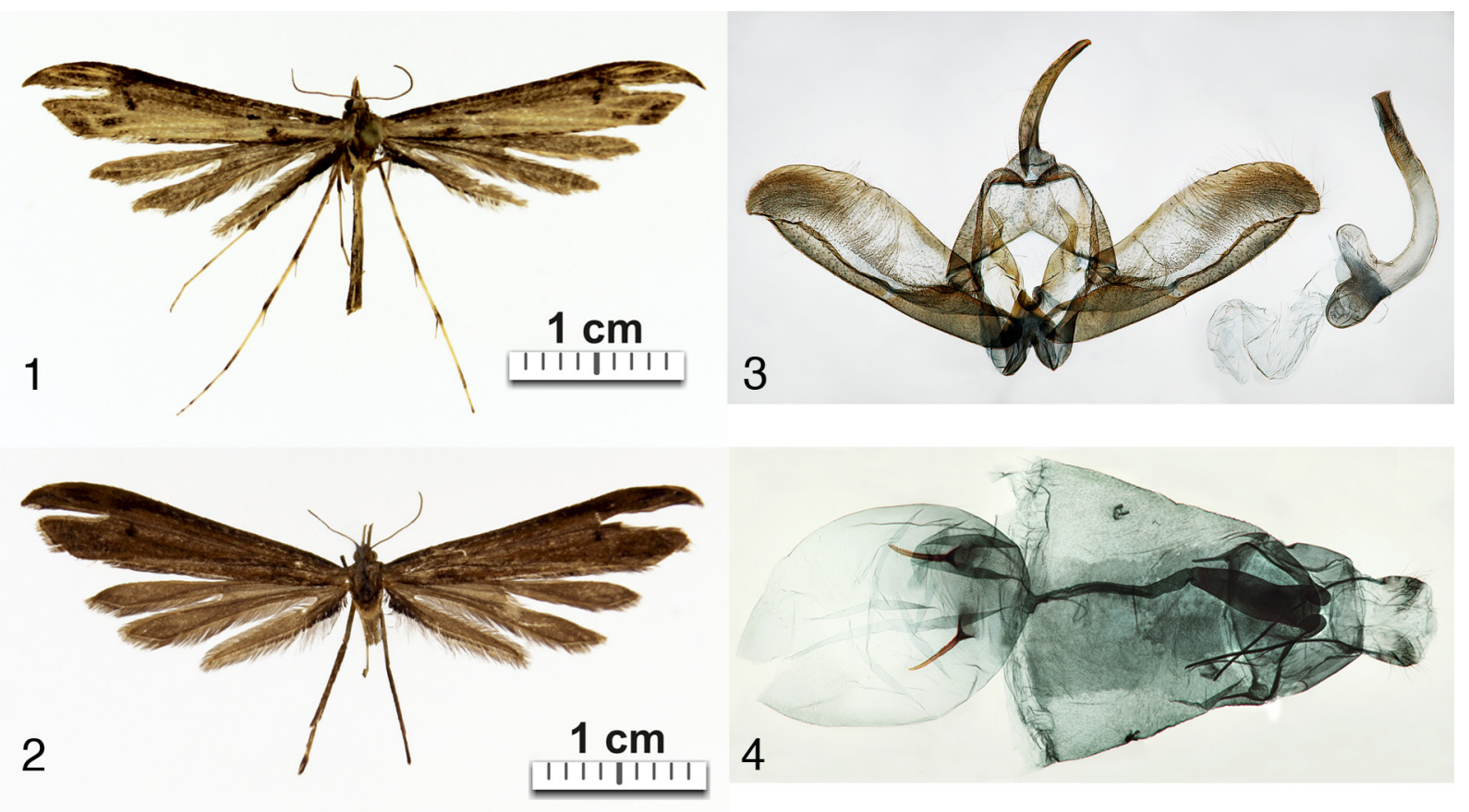

Figs 1-4. Platyptilia fletcheri Ustjuzhanin \& Kovtunovich sp. nov. 1. Adult, holotype, §̊, habitus (BMNH 21796). 2. Adult, paratype, $\widehat{\jmath}$, melanistic color (BMNH 21801). 3. Male genitalia, holotype. 4. Female genitalia, paratype (BMNH 21802). 
of the saccus. In the female genitalia the new species resembles Platyptilia sabia (Felder \& Rogenhofer, 1875 ) by the shape of the antrum, but differs from it by the more narrow ostium and shorter ductus.

\section{Etymology}

The species is named after the famous British entomologist David Stephen Fletcher, member of the 1952 expedition to the Rwenzori Mountains.

\section{Material examined}

Holotype

UGANDA: đ, Ruwenzori Range, Nyamaleju, 10,530 ft, 14-19 Jul. 1952, D.S. Fletcher, Ruwenzori Exped. B.M. 1952-566 (BMNH 21796).

\section{Paratypes}

UGANDA: $2 \hat{\delta} \hat{\partial}$, same data as holotype (BMNH 21800, CUK 244); $1 \hat{\alpha}$, Ruwenzori Range, Lake Mahoma, 9,600 ft, 12 Jul. 1952, D.S. Fletcher (BMNH 21797); 1 q Kigezi Dist., Mt Mgahinga, 8,000 ft, 22-27 Nov. 1934, F.W. Edwards (BMNH 21802); 1 ภ, 2 우우, Ruwenzori Range, Namwamba Valley, 6,500 ft, Dec. 1934-Jan. 1935, F.W. Edwards, B.M.E. Afr. Exp. B.M. 1935-203 (BMNH 21801, BMNH 21799, CUK 245).

RWANDA: 1 đ, Kisiba, Bugoie Forest, W Kivu, 8,500 ft, Nov. 1921, T.A. Barns (BMNH 21798); 2 우, Virunga Mts, Lake Kivu, 10,000 ft, Oct. 1921, T.A. Barns (BMNH 22764).

\section{Description}

EXTERNAL CHARACTERS. Wingspan 38-40 mm (holotype: $40 \mathrm{~mm}$ ). Head, thorax and tegulae brown-grey. Labial palpi straight, brown, three times as long as than eye diameter; third segment narrowed at tip and bent down. Antennae thin, brown. Fore wings brown-grey. Costal margin significantly darker than medial area. Two brown spots near wing base. Two fuzzy brown spots not reaching cleft. First lobe with yellowish longitudinal stripes, apical part tapered. Second lobe pale-grey with dusting of brown scales in form of shapeless brushstrokes. Fringe pale grey inside cleft, brown-grey at outer wing margin, darkbrown in basal part. Hind wings unicolorous, pale grey. Third lobe fringe with well defined black hairs at outer margin, most intensively expressed in basal part. Abdomen grey, rather long. Hind legs long, pale-brown, noticeably darkened at base of spurs.

Male genitalia. Valves symmetrical. Apex isolated and drawn downwards. Sacculus wide in basal part, then narrowing and slightly widened in distal part. Tegumen bilobed. Uncus narrow, slightly curved, tapered at apex. Juxta narrow, arched. Anellus arms long, wide in basal part, strongly narrowed and slightly bent inward in distal part. Saccus with proximate wedge-like outer edge and with triangular process from above, at its inner side. Phallus curved in centre, bluntly rounded, basal process straight, equal to length of coecum. Vesica with thin spinous cornutus in distal part of phallus.

Female genitalia. Papillae anales oval, narrow. Apophyses posteriores thin, long, three times longer than papillae anales. Apophyses anteriores also long, slightly shorter than posteriores ones, with small, spinous process in distal part. Ostium flat. Antrum wide, its length twice the length of papillae anales. Ductus bursae narrow, 1.5 times longer than antrum, with thin sclerite in middle part. Ductus seminalis near junction with bursa copulatrix. Bursa copulatrix large, oval, with two short, straight signa tapered to apices.

\section{Remarks}

The new species is characterized by the bright variation in the color of the wings. Half of the 11 type specimens have melanistic color. The species inhabits the mountainous areas of 1980-3210 m above sea level. 


\section{Distribution}

Uganda, Rwanda.

\section{Flight period}

July, October-January.

Platyptilia stanleyi Ustjuzhanin \& Kovtunovich sp. nov. urn:1sid:zoobank.org:act:5429545B-1FA2-469C-BF69-A81605ADAEA2

Figs 5-6

\section{Diagnosis}

Platyptilia stanleyi Ustjuzhanin \& Kovtunovich sp. nov. can be distinguished by its giant wingspan, which is unique among all the species of the genus Platyptilia as well as among all the African Pterophoridae. In the male genitalia the new species resembles Platyptilia fletcheri Ustjuzhanin \& Kovtunovich sp.nov. in the shape of the phallus and uncus, but clearly differs from it by the short and wide anellus arms and the fold on the inner side of the sacculus.

\section{Etymology}

The species is named after the famous British traveler, journalist and explorer of Africa, Henry Morton Stanley, the first European who visited the Rwenzori Mountains in 1876.

\section{Material examined}

\section{Holotype}

UGANDA: $\widehat{O}$, Ruwenzori Range, Nyamaleju, 10,530 ft, 14-19 Jul. 1952, Ruwenzori Exped. B.M. 1952-566, D.S. Fletcher (BMNH 21803).

\section{Description}

\section{Male}

EXTERNAL CHARACTERS. Wingspan $49 \mathrm{~mm}$. Thorax and tegulae brown-grey, head noticeably paler. Labial palpi straight, twice as long as eye diameter; third segment narrowed at top and bent down. Antennae thin, brown. Fore wings brown. Medial area slightly clarified. Dark brown spot in middle part of first quarter of wing. Two other spots (poorly expressed and slightly fuzzy) near cleft. First lobe dark brown in apical part. Second lobe significantly darker than basic wing color. Fringe inside cleft brown-grey; grey at outer margin of wing, with bunches of dark brown cilia. Hind wings unicolorous, pale grey. Third lobe fringe with well expressed black cilia at outer margin, from middle of wing to base of lobe. Abdomen brown. Hind legs long, brown, with portions of dark scales at base of spurs and in distal part.
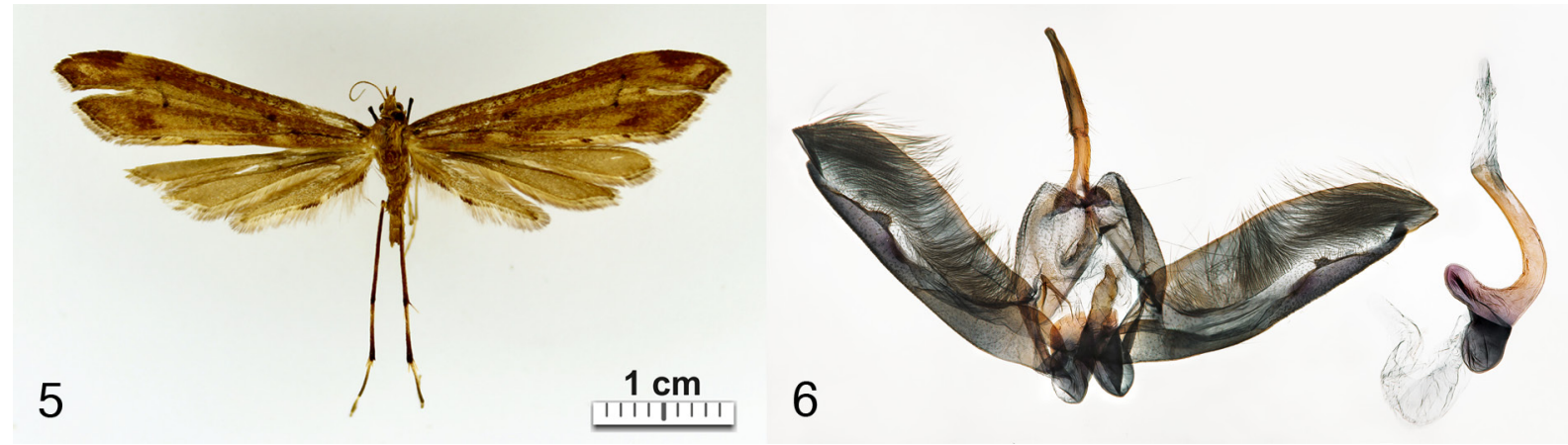

Figs 5-6. Platyptilia stanleyi Ustjuzhanin \& Kovtunovich sp. nov., holotype, $ð(B M N H ~ 21803)$. 5. Adult, habitus. 6. Male genitalia. 
Male genitalia. Valves symmetrical. Apex isolated and slightly tapered. Sacculus wide in basal and middle part; distal part significantly narrowed. Fold on inner side of sacculus. Tegumen bilobed. Uncus narrow, rather long, slightly widened in middle part and tapered at apex. Anellus arms short, wide, tapered only at apex. Saccus with proximate wedge-like outer edge and with triangular process from above, on its inner side. Phallus short, curved in center and rounded at base; basal process long, equal to length of coecum. Vesica with thin, needle-shaped cornutus in distal part of phallus.

\section{Female}

Unknown.

\section{Distribution}

Uganda.

\section{Flight period}

July.

\section{Acknowledgments}

The authors are grateful to Kevin Tuck, the former curator of the Microlepidoptera collection at the Natural History Museum (London, UK) for access to the Pterophoridae collections and granting a loan of the museum material for examination.

\section{References}

Gielis C. 2003. Pterophoroidea \& Alucitoidea (Lepidoptera). World Catalogue of Insects 4: 1-198. http://dx.doi.org/10.1002/mmnd.20030500211

Gielis C. 2008. Ten new species of Afrotropical Pterophoridae. Zoologische Mededelingen 82: 43-57.

Gielis C. 2011. Notes on some African Pterophoridae, with description of new species (Lepidoptera). Boletin de la Sociedad Entomologica Aragonesa (S.E.A.) 49: 33-63.

Kovtunovich V.N., Ustjuzhanin P.Ya. \& Murphy R. 2014. Plume moths of Malawi (Lepidoptera: Pterophoridae). Zootaxa 3847: 451-494. http://dx.doi.org/10.11646/zootaxa.3847.4.1

Meyrick E. 1924. Zoological results of the Swedish expedition to Central Africa, 1921. Insecta 4: Microlepidoptera. Arkiv för Zoologi 16 (14): 1-2.

Meyrick E. 1932. Entomological expedition to Abyssinia 1926-27. Microlepidoptera. Transactions of the Entomological Society of London 80: 107-109.

Meyrick E. 1938. Exploration du Parc National Albert. Mission G.F. Witte (1933-1935). Fasc. 14. Pterophoridae, Tortricina and Tineina: 3-28. Institut des Parcs Nationaux du Congo belge, Brussels.

Manuscript received: 8 October 2015

Manuscript accepted: 10 November 2015

Published on: 18 January 2016

Topic editor: Koen Martens

Desk editor: Kristiaan Hoedemakers 
Printed versions of all papers are also deposited in the libraries of the institutes that are members of the EJT consortium: Muséum national d'Histoire naturelle, Paris, France; Botanic Garden Meise, Belgium; Royal Museum for Central Africa, Tervuren, Belgium; Natural History Museum, London, United Kingdom; Royal Belgian Institute of Natural Sciences, Brussels, Belgium; Natural History Museum of Denmark, Copenhagen, Denmark. 